\title{
Correction to: Development of an autotrophic fermentation technique for the production of fatty acids using an engineered Ralstonia eutropha cell factory
}

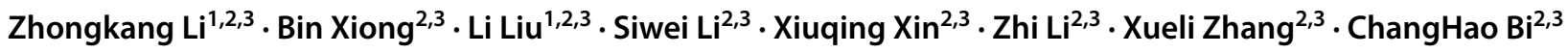

Published online: 10 April 2019

(c) Society for Industrial Microbiology and Biotechnology 2019

\section{Correction to: \\ Journal of Industrial Microbiology \& Biotechnology \\ https://doi.org/10.1007/s10295-019-02156-8}

The article Development of an autotrophic fermentation technique for the production of fatty acids using an engineered Ralstonia eutropha cell factory, written by Zhongkang Li, Bin Xiong, Li Liu, Siwei Li, Xiuqing Xin, Zhi $\mathrm{Li}$, Xueli Zhang, ChangHao Bi, was originally published electronically on the publisher's internet portal (currently SpringerLink) on 27 February 2019 with open access. With the author(s)' decision to step back from Open Choice, the copyright of the article changed on 23 March 2019 to () Society for Industrial Microbiology and Biotechnology 2019 and the article is forthwith distributed under the terms of copyright.

The original article has been corrected.

The original article can be found online at https://doi.org/10.1007/ s10295-019-02156-8.

Xueli Zhang

zhang_xl@tib.cas.cn

$\triangle$ ChangHao Bi

bi_ch@tib.cas.cn

1 University of Sciences and Technology of China, Hefei 230026, People's Republic of China

2 Tianjin Institute of Industrial Biotechnology, Chinese Academy of Sciences, Tianjin 300308, People's Republic of China

3 Key Laboratory of Systems Microbial Biotechnology, Chinese Academy of Sciences, Tianjin 300308,

People's Republic of China 